\title{
New Challenges, New Opportunities and New Approaches for College Students Work in the Era of "Internet Plus"
}

\author{
Menglin Xu \\ Nanyang Institute of Technology, Nanyang, China \\ jiumengni@163.com
}

Keywords: University Student; Internet Plus; Student Management

\begin{abstract}
Internet is a double-edged sword that brings about multi-aspect impacts to contemporary university students. With the arrival of the "Internet Plus" era, new impacts and challenges also come along to college students' work. College students should seize the opportunity of the Internet reform and strengthen the innovation of students' management in terms of the management concepts and modes, therefore to take full advantage of the Internet technology and to carry out the students ' daily management and thought management.
\end{abstract}

\section{Introduction}

During the NPC \&CPPCC in 2015, Vice Premier Li Keqiang put forward the "Internet Plus" plan in the government work report, since then, "Internet Plus" has become the most trending noun in the field of Internet, which also means that the national colleges and universities have entered the "Internet " era featuring the interconnection of all things. For colleges and universities, the Internet is a double-edged sword, which can provide richer and more prompt information as well as multi-element communication platform, but it can also significantly influence college students in terms of their outlook on life, the sense of worth, and the world view. Partially, they are negative effects, such as the spread of various vulgar information, which results in students' personality distorted or the issues referring the alteration of college students' outlook on life, the sense of worth, and the world view. Coupled with the emphasis on individual value among the current college students of post $95 \mathrm{~s}$, there are more problems and challenges waiting to be faced by the students when it comes to their work. For the personnel engaged in student work field, the Internet provides a great amount of management channels indeed, but it also poses many problems, such as the appearing of more regulatory loopholes. Therefore, exploring the new way of college students ' management in the era of "Internet Plus" has become a hot spot that attract attention from the field of academia.

\section{The New Challenges College Students Face Concerning Their Work in the Era of "Internet Plus"}

\section{The Negative Influence Brought by Internet on Students ' Political Ideas}

"Internet Plus" has become an overwhelming environment where students being cultivated. A relevant survey shows that currently, China's largest netizen group is young people, especially young college students, who accounted for a very large proportion. In addition to the establishment of a variety of learning platforms and communication platforms, college students' learning and regular life are completely under the network environment. The Internet has not only become a new way of lifestyle and learning method for college students, but has also become the most important way to influence college students ' outlook on philosophy, the sense of worth, and the world view. Especially the spread of vulgar information has posted new challenges to the ideological education work of college students [1].

\section{The Adverse Effects of the Internet on the Physical and Mental Health of the Students}

The current widespread problem is the tension and deterioration concerning dormitory relationship caused by chronic and long-term students' online game addicted issue. Some students often stay up through nights to play online games, which enormously harmed other students' daily 
life and studying. Given that the relationship between the dorm mates cannot be coordinated after a long time, severe conflicts and emotional confrontations will very likely come into being. Contributed by long-term sleep deprivation, depression, and intensified dormitory conflict, some students may experience psychological problems, which puts forward the current management of college students new challenges [2].

\section{The Low Barriers to the Network Led to Frequent Dishonesty Among Students}

The network dishonesties such as spreading false information, publishing irresponsible speech, provoking incident, and promoting rumors have been attracting widespread concern in the society. In an era of Internet, everyone can access we-media, publish information, and spread comments. In addition, due to the continuous facilitation of the network media, the information spread-out can be achieved by various means and methods. But the fact is that college students have not yet fully formed their life outlook, world view, and the sense of value, and they are lack of correct cognition for various things. What's more, considering the college students are often in a relatively impulsive and reckless mental stage, it is fairly prone for them to publish irresponsible remarks through network, thus to bring upon negative impact to schools and communities, It could further affect the stability of the society and endanger public interest. Some college students tend to cry out severely negative emotions through network once there is any objection against their teachers or school policy. All of these have imposed significant difficulty referring the management of the students.

\section{The New Opportunities for the Work of College Students under the Era of "Internet Plus"}

\section{Improve Work Efficiency with the Utilization of Network Media}

On the one hand, thanks to the new media network, counselors can deal with related work in a more efficient manner; an indispensable work element in counselors' work is to release various notice. Through new media, such as WeChat, QQ and other platforms, the information can be delivered to students and everyone will be notified promptly. On the other hand, holding a meeting to discuss the issue is also part of the daily work of counselors. Now a part of the college students who bear strong self-awareness are very ungrateful when it comes to the traditional one-way indoctrination of the information. With the openness and timeliness of new network media, and the realization of real-time interaction with students, the constraints of time and space can be greatly phased out, therefore to dismiss the resistance of the students.

\section{Improve the Work Relevance and Interaction with the Utilization of Network Carriers}

Some of the students have a sense of awe and veneration towards the teachers, which leads to the difficulty of face to face communication between the students and the counselors. Fortunately, with the interaction of various new media that is becoming more and more well-round, counselors can use these new media to send voice messages and communicate with students, in which process the expression can be delivered more comprehensively and meticulously, thus to break the voiceless and impersonal disadvantage of traditional media and achieve zero-distance communication.

\section{The New Way of Working for College Students in the Era of "Internet Plus"}

\section{Follow the Trend of Network Development, Modify Work Consciousness, and Innovate Work Concept}

In the era of "Internet Plus", colleges and universities should attach more attention to the ideological guidance referring network to seize the discourse power in leading the dynamic thinking pattern online. The traditional way of education and management can no longer meet the requirements of the development of education management under the new era. As the main responsible person for the management of college students, we must adapt to the requirements of the new era, change the old educational philosophy, earnestly study and actively face up the challenges brought by network information environment. And it is inevitable to improve the work methods, to establish student-centered and thought-oriented management concept. We shall equip ourselves with open mind, properly utilize the network tools and means to strengthen student cultivation, promote the undergraduate education in the era of "Internet Plus" [3]. 


\section{Strengthen the Construction of Student Work Team and Enhance the Network Information Using Capabilities and Influence}

Under the network information environment, college student managers should not only keep in touch with students, maintain a friendly and authoritative image, but also need to bear keen sensibility and familiarity to network environment and media. The staff should be able to enter the network environment in-depth as a decent player to engage in a variety of concepts and ideological exchanges to ensure that the campus network environment is healthy and safe [4]. Make full use of the network environment in a variety of channels and means to keep informed of the ideological changes and dynamic activities of college students; properly carry out the dynamic assessment and deviation prevention of students' mental make-up. Fully grasp the changes in students' thinking, timely collect public opinion, and promptly adjust the students' management methods and contents. Firmly grasp the dynamics of the students through the Internet platform, so that the college students work managers can act as the authoritative leaders and educators of the students' ideological dynamic [5].

\section{Using Network Media to Improve Student Management}

The main students 'problems faced by college students' managers include students' learning problems, interpersonal issues, mental health problems, emotional conflicts and other aspects. College students managers can take full advantage of a variety of Internet platform resources and the great amount of media, including WeChat, microblog, QQ, forum, Post bar, E-mail, and so forth, With them, the managers can build a multi-level, multi-platform, and multi-channel student management, platform to serve the communication between teachers and students, so that teachers can keep abreast of the students nowadays concerns and their ideological dynamics during the current stage, therefore to better guide students, enhance the timeliness of the students work and improve the work effectiveness.

\section{Use Network to Improve the Education System of Extracurricular Class}

Through network media, colleges and universities can establish extracurricular classes with a variety of forms and a wide range of contents, such as online public class, expert lectures, professional forums, innovation, entrepreneurship, etc. Through the network channel, the interaction between students and teachers can be enhanced. Timely education counseling help can be provided to the students in need and improve the effect of students' self-learning, self-cultivation, and self-improvement. With the access of network, we shall carry out ideological guidance and seize the discourse right, therefore to comprehensively cover various aspects concerning college students' studying and campus life and to promote the refined and scientific student management work.

\section{References}

[1] J.L. Xie. Journal of Chuxiong Normal University, (2015) No.02, p.69.

[2] Z.B. Liang. Journal of Jilin TV \& Radio University, (2016) No.6, p.126.

[3] X.P. Li. Science and Technology Guide (Update), (2016) No.3, p. 242.

[4] H.M. Ma. Higher Education Research, (2016) No.45, p.145.

[5] G.X. Jiang. School Party Building and Ideological Education, (2015) No.7, p.175. 